Félix Héctor Rígoli ${ }^{1}$

\title{
REGULAÇÃO PROFISSIONAL OU INTERPROFISSIONAL DO TRABALHO EM SAÚDE? DESAFIOS PARA OS SISTEMAS DE SAÚDE NA ÍNDIA, ESTADOS UNIDOS, FRANÇA E BRASIL
}

Professional or interprofessional regulation of work in health? Challenges for health systems in India, United States, France and Brazil

${ }^{1}$ Universidade de São Paulo. São Paulo/SP, Brasil.

Correspondência: felix.rigoli@gmail.com

Recebido: 16/08/2018 
Não muito tempo atrás, a decisão pela formação em saúde, a prática profissional e outros aspectos relacionados ao seu exercício eram considerados dados da realidade relativamente estáveis e que dependiam principalmente de decisões e possibilidades individuais. Isso não significava que o Estado, não tivesse algum papel, especialmente na profissão médica; na maioria dos casos, ele atuava como avalista dos corpos profissionais. No entanto, o crescente papel das políticas de saúde como políticas públicas - somado a alguns escândalos de má prática que chegaram à opinião pública - forçou a inclusão dos mecanismos regulatórios como parte das funções do Estado.

Essas funções são exercidas em formatos muito diferentes, como pode ser analisado nas experiências da Índia, Estados Unidos, França e Brasil, que constam nesta edição da Revista de Direito Sanitário. Em geral, seria possível dizer que existe um continuum que vai desde a autorregulação dos órgãos profissionais em compartimentos estancos até modelos flexíveis com participação dos usuários dos serviços. Ainda que se possa considerar, no senso comum, que existem diferenças entre o que faz um médico, um enfermeiro ou um odontólogo, as variações internacionais no escopo da prática dos profissionais de saúde sugerem que os agrupamentos de habilidades em profissões são geralmente arbitrários e se devem mais a costumes, tradições, incentivos, política profissional e poder do que às habilidades demostráveis ou aos conteúdos curriculares dos programas de formação.

As tentativas das profissões de lavrar em pedra regras para escopo de sua prática resultaram no uso ineficiente e na escassez de profissionais em muitas áreas. Em alguns casos, as regras impedem que esses profissionais possam fornecer toda a gama de serviços para os quais foram treinados. Em outros, a falta de um quadro regulamentar coerente cria obstáculos à implementação de serviços de saúde eficientes, como nos serviços de atenção primária e a pacientes com doenças crônicas.

O conjunto de artigos aqui apresentados desenvolve questões mais gerais sobre por que há necessidade de regulação em um determinado campo basicamente, em razão dos conflitos potenciais e crescentes entre os interesses públicos e as motivações dos profissionais em questões que afetam bens públicos críticos, como vida, saúde e segurança. Devido a esses aspectos críticos, as regulações têm se tornado mais densas e diversificadas nos últimos cem anos, e as agências encarregadas de sua supervisão se multiplicaram na mesma medida, usando uma mistura de modalidades próprias e externas.

Segundo Dubois e Singh ${ }^{1}$, esse conjunto de instituições e agências pode ser classificado em:

${ }^{1}$ DUBOIS, Carl-Ardy; SINGH, Debbie. From staff-mix to skill-mix and beyond: towards a systemic approach to health workforce management. Human Resources for Health, v. 7, p. 87, 2009. ISSN: 1478-4491. Disponivel em: <https://human-resources-health.biomedcentral.com/track/pdf/10.1186/1478-4491-787>. Acesso em: 27 ago. 2018. https://doi.org/10.1186/1478-4491-7-87. 
(i) estruturas políticas que definem a distribuição de responsabilidades e poderes entre vários grupos ocupacionais;

(ii) regras, regulamentos e leis que regem o comportamento do provedor e as condições de trabalho;

(iii) órgãos reguladores que assumem o controle de atividades profissionais; e

(iv) políticas e legislação que fornecem incentivos aos profissionais de saúde para melhorar sua prática.

Como esses corpos produzem cada vez mais regulamentações, o treinamento e a prática da saúde podem ser mais rígidos e, portanto, menos sensíveis às necessidades da população. Por outro lado, o excesso de regulação é propício à sobreposição e contradição de competências. Esta é uma receita perfeita para o conflito jurídico, já que o estudo brasileiro de Aith et al mostra e classifica uma lista interminável de reivindicações de territórios profissionais que acabam possivelmente criando uma desregulação de fato por meio da judicialização infinita.

O exemplo da Índia no artigo de Dharmesh Kumar Lal mostra um campo ainda mais complexo, devido à diversidade do país e às diferentes orientações na prática de saúde, que utiliza referenciais muito diferentes - questionando, inclusive, os fundamentos de cientificidade, a chamada medicina ocidental, aceitos (embora bastante abalados) como únicos em outras realidades.

No caso francês, o artigo de Stéphane Brissy mostra como o interesse especial do governo em tornar realidade uma política de saúde universal progressivamente entra em choque com o desejo de cada grupo profissional de se autorregular. $\mathrm{O}$ fato de existirem múltiplos níveis de regulação cria um cenário em movimento, com órgãos reguladores que atuam em planos diferentes, mas que cruzam suas disposições entre si e com as iniciativas do Estado. As iniciativas de criar espaços de prática avançada e comum entre as antigas profissões ainda aparecem, neste momento, como uma “operação política e socialmente difícil”.

A análise de Jean Moore sobre os entraves nos Estados Unidos, por haver 50 diferentes regulações profissionais (uma por estado), mostra também um aspecto positivo: a possibilidade de testar e comparar resultados de cada modelo. Mostra também que, mesmo com o dinamismo com que esse aspecto vai evoluindo, práticas tão simples quanto a prescrição da vacina de influenza feita por farmacêuticos levaram dez anos para se estenderem a todos os estados. Finalmente, o exemplo dos Estados Unidos reforça as conclusões dos demais países, indicando como derrubar barreiras entre profissões é uma tarefa necessária para a expansão do sistema de saúde. Ao mesmo tempo, como no Brasil e na França, esse processo demostra o quanto ele é "longo, controverso e demandante". 
Ao longo da última década, muitos governos introduziram reformas na área de saúde com a promessa de melhor utilizar o espectro de prestadores de serviços de saúde por meio de trabalho em equipe interprofissional e integração dos serviços de saúde. Em contraste com as reivindicações retóricas do trabalho em equipe interprofissional, no entanto, a preparação educacional dos profissionais de saúde permanece relativamente arraigada no paradigma tradicional, que tem limitado oportunidades de aprendizagem interdisciplinar que preparem os profissionais para trabalhar cooperativamente entre os limites de cada especialidade. Os estudantes são treinados separadamente (inclusive com certos preconceitos sobre as demais profissões) e, no dia seguinte à formatura, no trabalho é dito a eles: "Agora vocês são uma equipe!".

Desenvolver novos papéis e buscar mais flexibilidade no uso dos profissionais de saúde requererá também uma avaliação das condições ambientais que influenciam as práticas concretas e os mecanismos contratuais dos profissionais de saúde, como pode ser visto no exemplo da França, onde se detalha o papel crucial dos sindicatos e dos empregadores.

Devido à multiplicidade de planos de ação, atores e forças envolvidas e aos entrecruzamentos de níveis regulatórios, esta edição da Revista pode deixar a impressão de que não existem saídas para os entraves aqui descritos. No entanto, olhando de forma mais panorâmica, o que se percebe é que a confusão aparente se corresponde com uma época de rompimento de paradigmas, na qual, como descreve Gramsci, "o novo ainda não acabou de nascer, e o velho ainda não acabou de morrer"2. Existe, portanto, a necessidade de, no meio de tantas tensões e contradições, manter um rumo firme: fazer do sistema de saúde e de seus profissionais um instrumento de efetivação do direito à saúde de toda a população.

\section{Referências}

DUBOIS, Carl-Ardy; SINGH, Debbie. From staff-mix to skill-mix and beyond: towards a systemic approach to health workforce management. Human Resources for Health, v. 7, p. 87, 2009. ISSN: 1478-4491. Disponível em: <https://human-resources-health.biomedcentral.com/track/ pdf/10.1186/1478-4491-7-87>. Acesso em: 27 ago. 2018. https://doi.org/10.1186/1478-4491-7-87.

GRAMSCI, Antonio. Quaderni del Carcere, Vol.1, No. 3. Torino, Einaudi, 4 vols.

\footnotetext{
${ }^{2}$ No original: "Il vecchio mondo sta morendo. Quello nuovo tarda a comparire". GRAMSCI, Antonio. Quaderni
} del Carcere, Vol.1, No. 3. Torino, Einaudi, 4 vols. p. 311. 
Rígoli F. H.

Félix Héctor Rígoli - Doutor em Ciências pela Faculdade de Medicina de Ribeirão Preto da Universidade de São Paulo (USP); mestre em Gestão de Saúde (Administration de Santé) pela Université de Montreal; graduado em Medicina pela Universidad de la Republica Uruguay. Especialista em Sistema de Saúde do Instituto Sul-Americano de Governo em Saúde da União das Nações Sul-Americanas (ISAGS-UNASUL).São Paulo/SP, Brasil. E-mail: felix.rigoli@gmail.com 